\title{
Complexation of Andrographolide, Mirabegron and Suvorexant and Bioactivity Study of the Complexes
}

\author{
Rajia Sultana ${ }^{a}$, Md. Zakir Sultan ${ }^{*}$
}

\section{Abstract}

Background: There are many ways to synthesize new drug molecules for more potent therapeutic efficacy with minimum side effects. The drugs may exhibit therapeutic effects independently or may interfere with each other. Method: In this study, new drug molecules were synthesized by drug-drug complexation way according to the calculated $\mathrm{w} / \mathrm{w}$ ratio. The complexes were prepared by solid-mixing method using pestle and mortar by adding equal amount of drugs to each other, then warmed at $50{ }^{\circ} \mathrm{C}$ for 4 hours and left at room temperature for overnight to obtain new drug complexes. The new drug complexes were distinguished by Differential Scanning Calorimetry (DSC) and Fourier-transform infrared spectroscopy (FTIR) with the biological activity. Results: The melting endothermic peaks of andrographolide-suvorexant, andrographolidemirabegron, and suvorexant-mirabegron complexes were found at $221.02{ }^{\circ} \mathrm{C}, 189.49^{\circ} \mathrm{C}$ and $115.78^{\circ} \mathrm{C}$, respectively which were different from the melting endotherms of andrographolide, suvorexant and mirabegron at 230.87 ${ }^{\circ} \mathrm{C}, 127.09{ }^{\circ} \mathrm{C}$ and $140.40{ }^{\circ} \mathrm{C}$, respectively. The FTIR spectra of the formed complexes showed the similar characteristics of the standard drugs. The cytotoxic effect of the drug complexes on HeLa cell line were

Significance | Synthesis of new drugs by complexation for therapeutic application higher ( $10 \%$ less survived HeLa cell, i.e. > $90 \%$ cell died) than the precursor drug molecules.

Conclusion: Our research findings that three new drug compounds were synthesized by complexation way which could be due to interaction of andrographolide and suvorexant; andrographolide and mirabegron, and suvorexant and mirabegron.

Keywords: Drug, Drug-drug Interaction, Synthesis, Differential Scanning Calorimetry, FTIR, Cytotoxicity, Andrographolide, Suvorexant and Mirabegron.

Abbreviations: A. Paniculata, Andrographis paniculata; DMSO, Dimethyl sulfoxide; DSC, Differential Scanning Calorimetry; FTIR, Fourier-transform infrared spectroscopy; HPLC, High performance liquid chromatography; DMEM, Dulbecco's Modified Eagles' medium; FBS, Fetal bovine serum.

\section{Introduction}

Drug-drug interaction is an important issue in clinical practice as well as in the discovery and development of new drugs. A large number of medications is used simultaneously that may increase the risks for drug interactions. The therapeutic effects of drugs may exhibit independently or may interfere or interact with each other. The interaction may be agonist or antagonist of one drug by another. Sometimes, multiple drug therapy is favorable to the patients and sometimes it causes serious adverse effects. Therefore, combinations of drugs chosen for investigation of drug-drug interactions are selected for alteration in the pharmacokinetics or pharmacodynamics of a narrow therapeutic index drug (Saha et al., 2013). Thus the drug interaction study is very much important in respect to both biopharmaceutics and pharmacology (Goodman, 1996; Saha et al., 2015).

\section{Author Affiliation}

a. Centre for Advanced Research in Sciences (CARS), University of Dhaka, Dhaka-1000, Bangladesh

\section{Please cite this article:}

Sultana R, Sultan MZ (2019). Complexation of Andrographolide, Mirabegron and Suvorexant and Bioactivity Study of the Complexes. Microbial Bioactives, 2(1), 076-081.
Edited by Md. Shamsuddin Sultan Khan, Western Sydney University, Australia. And accepted by the Editorial Board February 10, 2019 (Received for review July 4, 2018)
2209-2153/๑ 2018 MICROBIAL BIOACTIVES, a publication of Eman Research Ltd, Australia. This is an open access article under the CC BY-NC-ND license. (http://microbialbioactives.emanresearch.org). 
Andrographis paniculata (Burm. f.) Wall. Ex Nees belongs to the family of Acanthaceae which is called as Kalmegh or King of Bitters (Mishra, Sangwan, \& Sangwan, 2007; Rajani, Shrivastava, \& Ravishankara, 2000). It is an herbaceous plant and is found in tropical and subtropical Asia, Southeast Asia, and India (Jarukamjorn \& Nemoto, 2008). It has wide range of pharmacological application, which has been used either single or in combination with other drugs in various Indian traditional systems of medicine like Ayurveda and Sidda. Traditionally, mostly leaves and roots are used for different medicinal purposes in Asia and Europe that is also known as folklore remedy or as herbal supplement for health promotion or ailments (Jarukamjorn \& Nemoto, 2008). It possesses several phytochemical constituents with unique and interesting biological properties.

The bioactive compound 'andrographolide' is one of the major components of the plant $A$. paniculata. Andrographolide is a highly bitter, colorless crystalline compound (Mishra et al., 2007). Andrographolide is chemically described as $3 \alpha, 14,15,18$ tetrahydroxy-5 $\beta, 9 \beta \mathrm{H}, 10 \alpha$-labda-8, 12-dien-16-oic acid $\gamma$-lactone (Fig. 1A). The melting point of this compound is $228^{\circ} \mathrm{C}-230^{\circ} \mathrm{C}$ and [(2-hydroxy-2-phenylethyl) amino] ethyl] acetanilide or 2-amino-N[4-[2-[[(2R)-2-hydroxy-2-phenylethyl] amino] ethyl] phenyl]-4thiazoleacetamide (Fig. 1B).

Suvorexant is a selective, dual orexin receptor antagonist and the first drug in its class to reach the market. IUPAC name of suvorexant is [(7R)-4-(5-chloro-1, 3-benzoxazol-2-yl)-7-methyl-1, 4-diazepan-1yl]-[5-methyl-2-(triazol-2 yl) phenyl] methanone (Fig. 1C). It is a medication for the treatment of insomnia which is characterized by difficulties with sleep onset and/or sleep maintenance approved in the United States and Japan in late 2014 (Baxter et al., 2011; Patel, Aspesi, \& Evoy, 2015; Sutton, 2015). Some people reported that the drug caused a sleep disturbance such as a nightmare, sleep terror, or abnormal dream or to be more awake or even thoughts of suicide (Jacobson, Callander, \& Hoyer, 2014; Teresa Carr, 2016).

The principal purpose of the present study was to investigate complex formation for synthesizing new molecule with biological activity which could be due to interaction of andrographolide and suvorexant; andrographolide and mirabegron, and suvorexant and
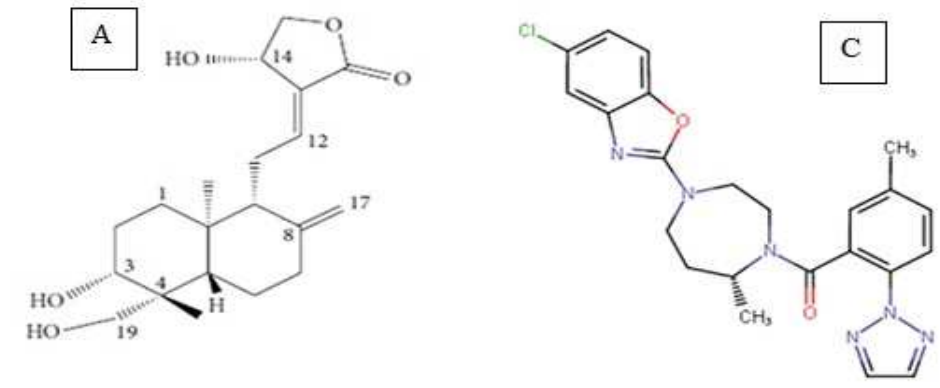

Figure 1 | Chemical structure of A) andrographolide (Nanduri et al., 2004), B) mirabegron (Takusagawa, Miyashita, Iwatsubo, \& Usui, 2012), and C) suvorexant (Coleman, Gotter, Herring, Winrow, \& Renger, 2017)<smiles>Nc1nc(CC(=O)Nc2ccc(CCNC[C@H](O)c3ccccc3)cc2)cs1</smiles>

the ultraviolet spectrum in ethanol, $\lambda_{\max }$ is $223 \mathrm{~nm}$. Traditionally it is used in the treatment of gastro-intestinal tract and upper respiratory infections, fever, herpes, sore throat, and a variety of other chronic and infectious disease (Mishra et al., 2007). In traditional Chinese medicine, it is a significant for cold property which is used to throw out the body-heat and to disperse toxins of the body (Deng, 1978; Jarukamjorn \& Nemoto, 2008). The Indian Pharmacopoeia reports that it is a predominant constituent of at least 26 Ayurvedic formulations (Jarukamjorn \& Nemoto, 2008; Mishra et al., 2007; WHO media center, 2007). It is commonly used for the prevention or treatment of cold in Scandinavian countries (Cáceres, Hancke, Burgos, \& Wikman, 1997; Jarukamjorn \& Nemoto, 2008).

Mirabegron is a potent $\beta_{3}$-adrenoceptor agonist that is recently approved by Food and Drug Administration for the prospective treatment of overactive bladder therapy (Takasu et al., 2007). The chemical name of mirabegron is (R)-2-(2-aminothiazol-4-yl)-4'-[2-

mirabegron.

\section{Methods}

\section{Materials}

Andrographolide, suvorexant and mirabegron were collected from authentic sources. HPLC grade methanol and chloroform were purchased from Sigma Aldrich, Germany. Nanopure water was used and collected from own source. The drug complexes of andrographolide, suvorexant and mirabegron were synthesized according to the calculated $\mathrm{w} / \mathrm{w}$ ratio. The complexes were prepared by solid-mixing method using pestle and mortar by adding equal amount of drugs to each other, then warmed at $50{ }^{\circ} \mathrm{C}$ for 4 hours and left at room temperature for overnight to obtain new drug complexes of andrographolide-suvorexant, andrographolide-mirabegron, and suvorexant-mirabegron (Sultana, Arayne, Rizvi, Haroon, \& Mesaik, 2013). 


\section{Characterizations}

\section{Differential Scanning Calorimetry (DSC)}

Complexes of the drugs were studied using DSC-60, Shimadzu Corporation, Japan. Sample was weighed and placed in a sealed aluminum pan and scanned from room temperature to $300^{\circ} \mathrm{C}$ with heating rate of $10{ }^{\circ} \mathrm{C} / \mathrm{min}$. The DSC analyses were performed of pure andrographolide, suvorexant, mirabegron and their binary mixtures.

\section{Fourier-transform infrared spectroscopy (FTIR)}

FTIR spectra of pure andrographolide, suvorexant, mirabegron and their binary complexes were recorded using $\mathrm{KBr}$ disk on FTIR spectro-photometer (IR prestige-21, Shimadzu, Japan).

\section{Cytotoxicity study}

Cytotoxicity study was done against Hela cell line. Hela is a human cervical carcinoma cell line that was maintained in DMEM (Dulbecco's Modified Eagles' medium) containing 1\% penicillinstreptomycin (1:1) and $0.2 \%$ gentamycin and $10 \%$ fetal bovine serum (FBS). HeLa Cells $\left(2.0 \times 10^{4} / 100 \mu \mathrm{L}\right)$ were seeded onto 96well plate and incubated at $37{ }^{\circ} \mathrm{C}+5 \% \mathrm{CO}_{2}$ for $24 \mathrm{~h}$. Later on, 100 $\mu \mathrm{L}$ of sample was added into each well and incubated for $48 \mathrm{~h}$ at 37 ${ }^{\circ} \mathrm{C}+5 \% \mathrm{CO}_{2}$. Then cytotoxic effect was evaluated under inverted light microscope. Duplicate wells were used for each sample.

\section{Results and Discussion}

Thermal analysis by DSC

The DSC thermograms of pure andrographolide, suvorexant, mirabegron and drug complexes are represented in Fig. 2A, Fig. 2B and Fig. 2C. From these figures it was found that the DSC thermogram of pure andrographolide showed a single endotherm peak at $230.87^{\circ} \mathrm{C}$ which was ascribed to drug melting (Rajani et al., 2000). The endothermic peak of pure mirabegron was also found at $140.40{ }^{\circ} \mathrm{C}$ (Patal \& Patal, 2018), and at $127.09{ }^{\circ} \mathrm{C}$ for the pure suvorexant which are correspond to the melting temperatures of the drugs respectively. The melting endothermic peaks of drug complexes like as andrographolide-suvorexant, andrographolidemirabegron, and suvorexant-mirabegron complexes were found at $221.02{ }^{\circ} \mathrm{C}, 189.49{ }^{\circ} \mathrm{C}$ and $115.78{ }^{\circ} \mathrm{C}$, respectively which were different from the melting endotherms of andrographolide, suvorexant and mirabegron. Therefore, these different melting endotherms indicated the different compounds which were formed from interaction of the drugs each other.

\section{Fourier-transform infrared spectroscopy (FTIR)}

The FT-IR spectrum of the adrographolide (Fig. 3A) showed the characteristic absorption bands at $1369.46 \mathrm{~cm}^{-1}$ (bending vibration of $-\mathrm{CH}_{3}$ ), $1458.18 \mathrm{~cm}^{-1}$ (stretching vibration of $\mathrm{C}=\mathrm{C}$ bond), 1674.21, $1726.29 \mathrm{~cm}^{-1}$ (stretching vibration of $\mathrm{C}=\mathrm{O}$ ), 2927.94, $2968.45 \mathrm{~cm}^{-1}$ (stretching vibration of C-H), 3323.35, $3398.57 \mathrm{~cm}^{-1}$ (stretching vibration of hydrogen bonded $\mathrm{O}-\mathrm{H}$ ) and 3703.33, $3778.55 \mathrm{~cm}^{-1}$ (stretching vibration of free $\mathrm{O}-\mathrm{H}$ ) (Mohana \& Umarani, 2016; Sajeeb, Kumar, Halder, \& Bachar, 2015). The spectrum of pure mirabegron (Fig. $3 \mathrm{~B}$ ) revealed the characteristics peaks at $1112.93,1336.67 \mathrm{~cm}^{-1}$ (stretching vibration of $\mathrm{C}-\mathrm{N}$ ), $1413.82,1523.76 \mathrm{~cm}^{-1}$ (stretching vibration of $\mathrm{C}=\mathrm{C}$ bond), 1602.85 cm-1 (stretching vibration of $\mathrm{C}=\mathrm{N}$ ), $1651.07 \mathrm{~cm}^{-1} \quad$ (stretching vibration of $\mathrm{C}=\mathrm{O}$ ), $2852.72,2926.01 \mathrm{~cm}^{-1}$ (stretching

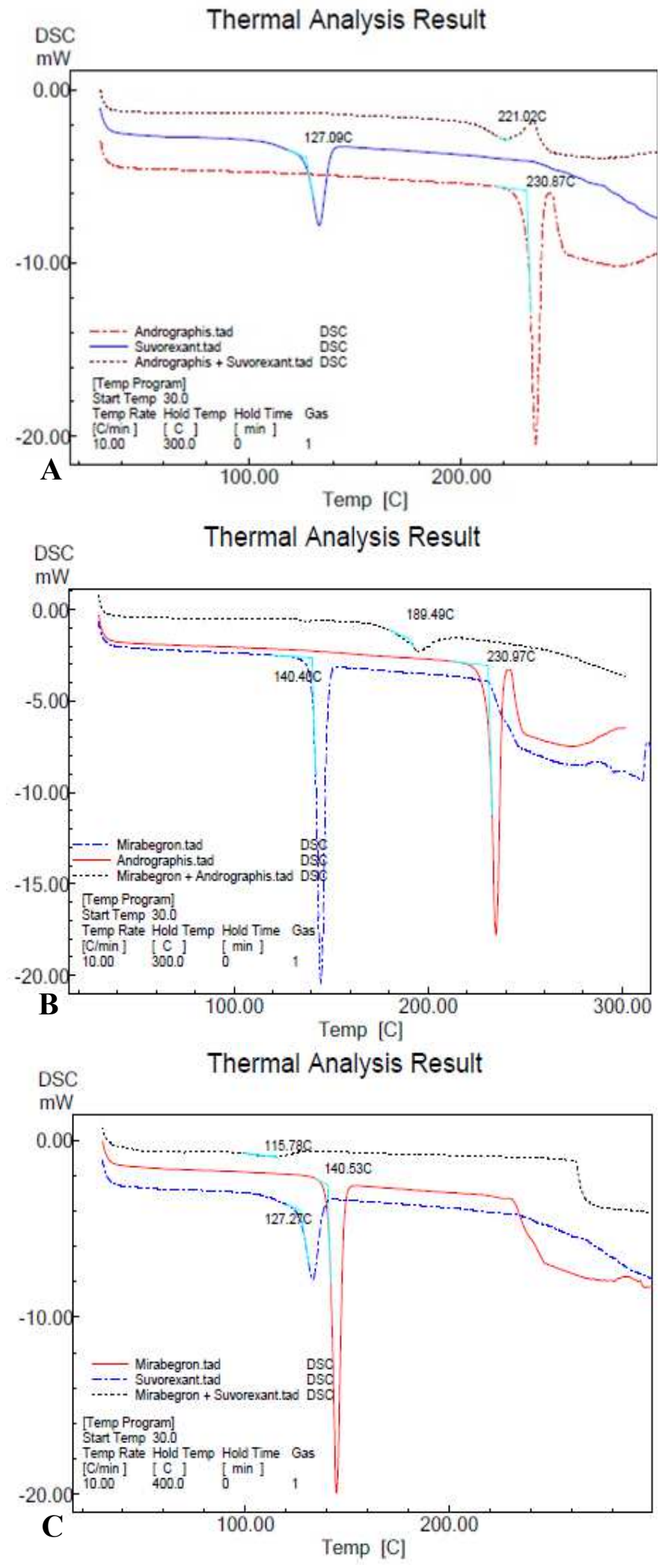

Figure 2 Thermal analysis of drugs and their complexes. A. DSC curve of andrographolide, suvorexant and their complex. B. DSC curve of andrographolide, mirabegron and their complex. $C$. DSC curve of suvorexant, mirabegron and their complex 

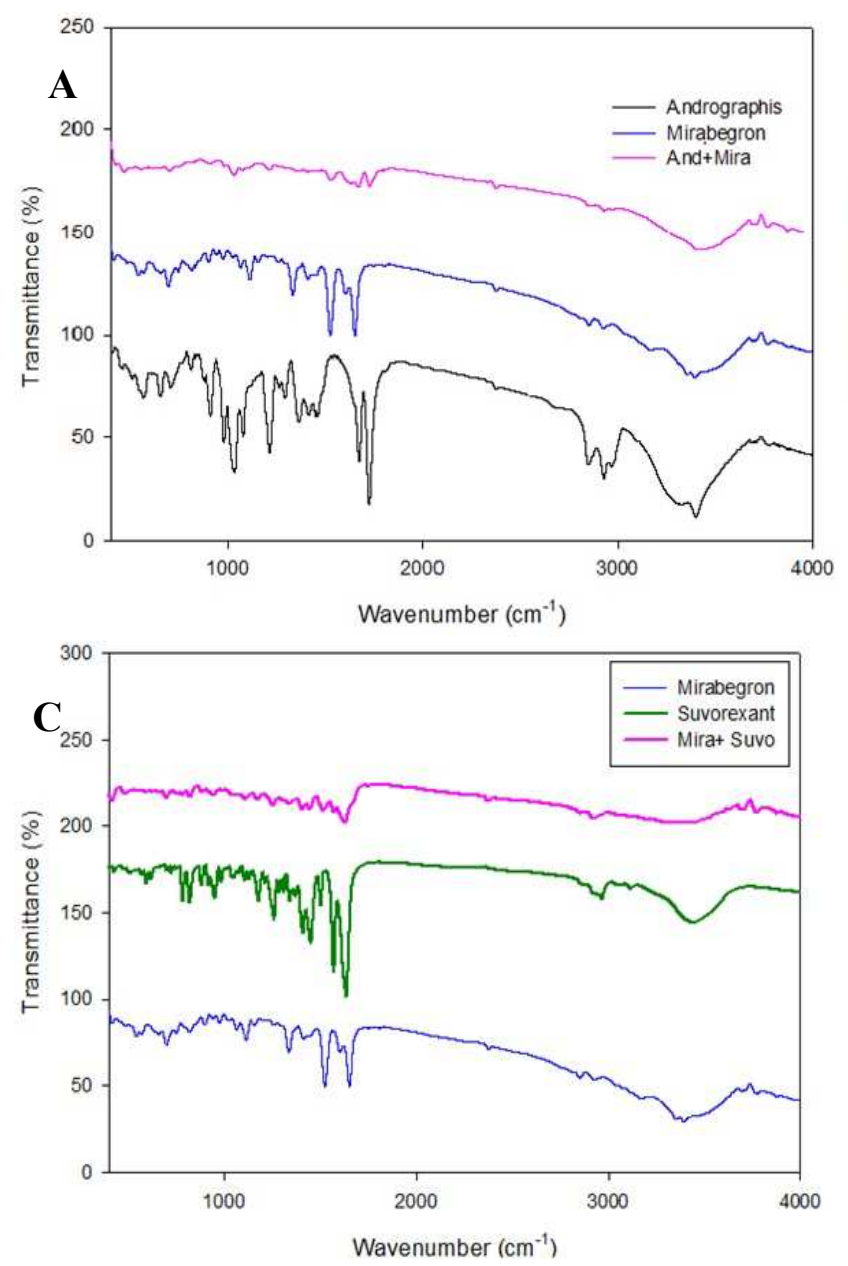

vibration of C-H), 3170.97, 3352.28, $3394.72 \mathrm{~cm}^{-1}$ (stretching vibration of $\mathrm{N}-\mathrm{H}$ ), 3689.83, $3774.69 \mathrm{~cm}^{-1}$ (stretching vibration of free $\mathrm{O}-\mathrm{H}$ ) (Patal \& Patal, 2018). The spectrum of pure suvorexant (Fig. 3C) expressed characteristics peaks at $1047.35 \mathrm{~cm}^{-1}$ (stretching vibration of $\mathrm{Cl}$ ), 1178.51, $1257.59 \mathrm{~cm}^{-1}$ (stretching vibration of C-N), 1409.96, $1450.47,1571.99 \mathrm{~cm}^{-1}$ (stretching vibration of $\mathrm{C}=\mathrm{C}$ bond), $1631.78 \mathrm{~cm}^{-}$ ${ }^{1}$ (stretching vibration of $\mathrm{C}=\mathrm{O}$ ), 2966.52, $3118.90 \mathrm{~cm}^{-1}$ (stretching vibration of $\mathrm{C}-\mathrm{H}$ ), $3452.58 \mathrm{~cm}^{-1}$ (stretching vibration of $\mathrm{N}-\mathrm{H}$ ).

The FTIR spectrum of the complex compound of andrographis and mirabegron (Fig. 3A) observed the characteristic absorption bands at $1215.15 \mathrm{~cm}^{-1}$ (stretching vibration of C-N), $1527.62 \mathrm{~cm}^{-1}$ (stretching

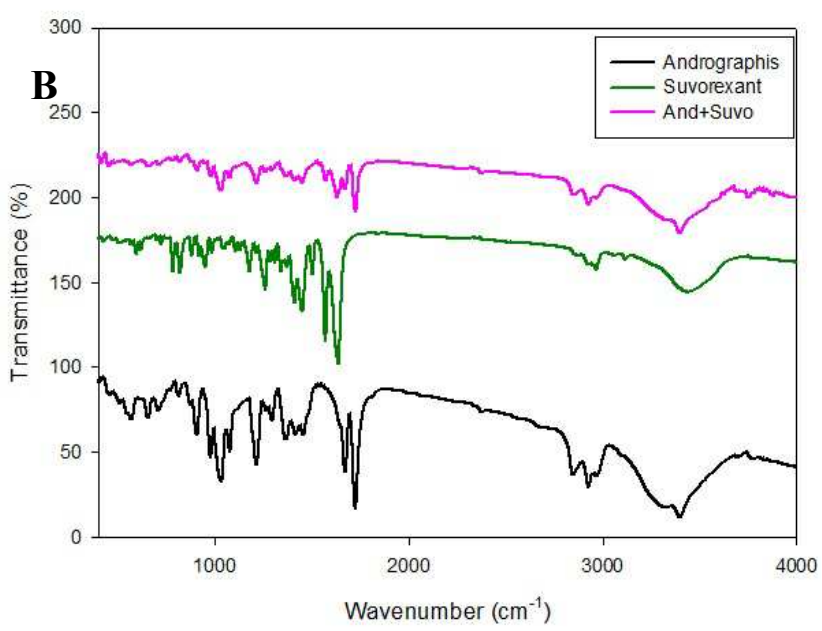

Figure 3 | A. FTIR spectrum of andrographolide, mirabegron and their complex. B. FTIR spectrum of andrographolide, suvorexant and their complex. C. FTIR spectrum of suvorexant, mirabegron and their complex.

Table 1 | Cytotoxic activity of andrographolide, suvorexant, mirabegron and complexes.

\begin{tabular}{lll}
\hline Sample ID & $\begin{array}{l}\text { Survival of } \\
\text { HeLa cells }\end{array}$ & Remarks \\
\hline Negative Control & $100 \%$ & \\
Positive Control & $>95 \%$ & Cytotoxicity was \\
Andrographolide & $>15 \%$ & observed against HeLa \\
Suvorexant & $>20 \%$ & cell line \\
Merabegron & $>18 \%$ & \\
Andrographolide-suvorexant complex & $<10 \%$ & \\
Andrographolide-mirabegron complex & $<10 \%$ & \\
Suvorexant-mirabegron complex & $<10 \%$ & \\
\hline
\end{tabular}

Note: Negative Control= HeLa cell, Positive Control= DMSO (Dimethyl sulfoxide) 
spectra of the formed compound of mirabegron and suvorexant (Fig. 3C) presented characteristic peaks at $1111.00,1255.66 \mathrm{~cm}^{-1}$ (stretching vibration of $\mathrm{C}-\mathrm{N}$ ), $1446.61,1518.05 \mathrm{~cm}^{-1}$ (stretching vibration of $\mathrm{C}=\mathrm{C}$ bond), $1751.36,1629.85 \mathrm{~cm}^{-1}$ (stretching vibration of $\mathrm{C}=\mathrm{O}$ ), 2854.65 , $2924.09 \mathrm{~cm}^{-1}$ (stretching vibration of C-H), 3311.78, $3417.86 \mathrm{~cm}^{-1}$ (stretching vibration of $\mathrm{N}-\mathrm{H}$ ) $, 3693.66,3772.76 \mathrm{~cm}^{-1}$ (stretching vibration of free $\mathrm{O}-\mathrm{H})$.

\section{Cytotoxic activity}

The cytotoxic activity of the pure drugs (andrographolide, suvorexant, mirabegron) and drug complexes were quantified by exposure of these drugs to the specific cell lines. The cytotoxic activity of these drugs was examined against HeLa cell (Ferdous, Shishir, Khan, \& Hoq, 2018; Vasanthabharathi \& Jayalakshmi, 2018; Wu et al., 2017). Higher concentrations (2.5 mg/dose) of each sample of andrographolide, suvorexant, mirabegron and drug complexes were used separately for their cytotoxicity test. After 48 hour incubation, it was observed that the cytotoxic activity of the drug complexes on HeLa cell line were higher (10\% less survived HeLa cell, i.e. > $90 \%$ cell died) than the precursor drug molecules (Table 1).

\section{Conclusion}

The in vitro drug-drug interactions seem to positively change the beneficial effects on therapeutic outcomes, i.e. the complexes of andrographolide-suvorexant, andrographolide-mirabegron, and suvorexant-mirabegron showed different biological activities. In the discovery research phase to design new molecules, various in vitro and in vivo studies are required to determine the value of these new complexes to meet targeted medical needs. This research also indicated that concomitant intake of these drugs should attain more precautions.

\section{Competing financial interests}

The authors declare no competing financial interest.

\section{Author Contribution}

RS carried out the experimental works, analyzed the data and drafted the manuscript. MZS designed and supervised the research, and did meticulous revision of the manuscript.

\section{Acknowledgement}

The authors would like to acknowledge for the financial support provided by the Centre for Advanced Research in Sciences (CARS), University of Dhaka, Dhaka-1000, Bangladesh. The authors also express their gratitude to Mrs. Hasina Akhter Simol and Dr. Tania Hossain of the Centre for Advanced Research in Sciences (CARS), University of Dhaka, Dhaka-1000, Bangladesh for providing FTIR data and cytotoxicity assay data, respectively.

\section{References}

Baxter, C. A., Cleator, E., Brands, K. M. J., Edwards, J. S., Reamer, R. A., Sheen, F. J., ... Wallace, D. J. (2011). The First Large-Scale Synthesis of MK-4305: A Dual Orexin Receptor Antagonist for the Treatment of Sleep Disorder. Organic Process Research \& Development, 15(2), 367-375. https://doi.org/10.1021/op1002853

Cáceres, D. D., Hancke, J. L., Burgos, R. A., \& Wikman, G. K. (1997). Prevention of common colds with Andrographis paniculata dried extract. A Pilot double blind trial. Phytomedicine, 4(2), 101-104. https://doi.org/10.25163/microbbioacts.21010A0410130219
https://doi.org/10.1016/S0944-7113(97)80051-7

Coleman, P. J., Gotter, A. L., Herring, W. J., Winrow, C. J., \& Renger, J. J. (2017). The Discovery of Suvorexant, the First Orexin Receptor Drug for Insomnia. Annual Review of Pharmacology and Toxicology, 571), 509533. https://doi.org/10.1146/annurev-pharmtox-010716-104837

Deng, W. L. (1978). Preliminary studies on the pharmacology of the Andrographis product dihydroandrographolide sodium succinate. Newsletter Chinese Herbal Medicine, 8, 26-28.

Ferdous, U. T., Shishir, M. A., Khan, S. N., \& Hoq, M. M. (2018). Bacillus spp.: Attractive Sources of Anti-cancer and Anti-proliferative Biomolecules. Microbial Bioactives, 1(1), E033-E045. https://doi.org/10.25163/microbbioacts.11005B0408130818

Goodman, L. S. (1996). Goodman and Gilman's the pharmacological basis of therapeutics (Vol. 1549). McGraw-Hill New York.

Jacobson, L. H., Callander, G. E., \& Hoyer, D. (2014). Suvorexant for the treatment of insomnia. Expert Review of Clinical Pharmacology, 76), 711730. https://doi.org/10.1586/17512433.2014.966813

Jarukamjorn, K., \& Nemoto, N. (2008). Pharmacological Aspects of Andrographis paniculata on Health and Its Major Diterpenoid Constituent Andrographolide. Journal of Health Science, 54(4), 370-381. https://doi.org/10.1248/jhs.54.370

Mishra, S. K., Sangwan, N. S., \& Sangwan, R. S. (2007). Phcog Rev.: Plant Review Andrographis paniculata (Kalmegh): A Review. Pharmacognosy Reviews, 1(2), 283-298.

Mohana, S. J., \& Umarani, V. (2016). Isolation and Characterisation of Andrographolide from Andrographis Paniculata. World Journal of Pharmacy and Pharmaceutical Sciences, 5(9), 1954-1961.

Nanduri, S., Nyavanandi, V. K., Sanjeeva Rao Thunuguntla, S., Kasu, S., Pallerla, M. K., Sai Ram, P., ... Akella, V. (2004). Synthesis and structureactivity relationships of andrographolide analogues as novel cytotoxic agents. Bioorganic and Medicinal Chemistry Letters. https://doi.org/10.1016/j.bmcl.2004.06.090

Patal, D. A., \& Patal, D. J. (2018). Physicochemical characterization and in vitro dissolution enhancement of Mirabegron using solid dispersion method. World Journal of Pharmacy and Pharmaceutical Sciences, 75), 973-991.

Patel, K. V., Aspesi, A. V., \& Evoy, K. E. (2015). Suvorexant. Annals of Pharmacotherapy, 49(4), 477-483. https://doi.org/10.1177/1060028015570467

Rajani, M., Shrivastava, N., \& Ravishankara, M. N. (2000). A rapid method for isolation of andrographolide from Andrographis paniculata nees (kalmegh). Pharmaceutical Biology, 38(3), 204-9. https://doi.org/10.1076/1388-0209(200007)3831-SFT204

Saha, S., Begum, R., Rahman, A., Sultan, M. Z., Amran, M. S., \& Hossain, M. A. (2015). Evaluation of in vitro Interaction of Metformin with Ibuprofen in Aqueous Medium. Bangladesh Pharmaceutical Journal, 162), 189-194. https://doi.org/10.3329/bpj.v16i2.22303

Saha, S., Begum, R., Sultan, M. Z., Amjad, F. M., Amran, M. S., \& Hossain, M. A. (2013). In vitro Interaction of Metformin with Diclofenac in Aqueous Medium. Dhaka University Journal of Pharmaceutical Sciences, 11(2), 101-106. https://doi.org/10.3329/dujps.v11i2.14555

Sajeeb, B., Kumar, U., Halder, S., \& Bachar, S. C. (2015). Identification and Quantification of Andrographolide from Andrographis paniculata (Burm. f.) Wall. ex Nees by RP-HPLC Method and Standardization of its Market Preparations. Dhaka University Journal of Pharmaceutical Sciences, 14(1), 71-78. https://doi.org/10.3329/dujps.v14i1.23738 E076-E081 | MICROBIAL BIOACTIVES | Published online February 13, 2019 
Sultana, N., Arayne, M. S., Rizvi, S. B. S., Haroon, U., \& Mesaik, M. A. (2013). Synthesis, spectroscopic, and biological evaluation of some levofloxacin metal complexes. Medicinal Chemistry Research. https://doi.org/10.1007/s00044-012-0132-9

Sutton, E. L. (2015). Profile of suvorexant in the management of insomnia. Drug Design, Development and Therapy, 9, 6035-42. https://doi.org/10.2147/DDDT.S73224

Takasu, T., Ukai, M., Sato, S., Matsui, T., Nagase, I., Maruyama, T., ... Yamaguchi, O. (2007). Effect of (R)-2-(2-aminothiazol-4-yl)-4'-\{2-[(2hydroxy-2-phenylethyl)amino]ethyl\} acetanilide (YM178), a novel selective beta3-adrenoceptor agonist, on bladder function. The Journal of Pharmacology and Experimental Therapeutics, 321(2), 642-7. https://doi.org/10.1124/jpet.106.115840

Takusagawa, S., Miyashita, A., Iwatsubo, T., \& Usui, T. (2012). In vitro inhibition and induction of human cytochrome P450 enzymes by mirabegron, a potent and selective $\beta 3$-adrenoceptor agonist. Xenobiotica, 42(12), 1187-1196. https://doi.org/10.3109/00498254.2012.700140

Teresa Carr. (2016). FDA Fields Complaints on Sleeping Pill Suvorexant. Consumer Reports.

Vasanthabharathi, V., \& Jayalakshmi, S. (2018). Bioactive potential from Marine sponge Callyspongia diffusa associated Pseudomonus fluorescens BCPBMS-1 and Penicillum citrinum. Microbial Bioactives, 1(1), 8-13. https://doi.org/10.25163/microbbioacts.11002A2221300318

WHO media center. (2007). WHO monographs on selected medicinal plants (Vol. 3). Geneve: World Health Organization. Retrieved from http://www.who.int/medicines/areas/traditional/

Wu, Y. S., Ngai, S. C., Goh, B. H., Chan, K. G., Lee, L. H., \& Chuah, L. H. (2017). Anticancer activities of surfactin potential application of nanotechnology assisted surfactin delivery. Frontiers in Pharmacology, 8(OCT), 1-22. https://doi.org/10.3389/fphar.2017.00761 